\title{
Institutionalizing Patient Safety Culture: A Strategic Priority for Healthcare in India
}

\author{
Anupama Shetty ${ }^{1,}$ Harshad Thakur ${ }^{2}$ \\ ${ }^{I}$ (School of Health Systems Studies, Tata Institute of Social Sciences, India) \\ ${ }^{2}$ (Centre for Public Health, School of Health Systems Studies, Tata Institute of Social Sciences, India)
}

\begin{abstract}
Fledgling steps in the form of policy measures, surveillance mechanisms and safety initiatives have been taken in the Indian healthcare context to address the increasing evidence base of patient safety events. The paper examines whether structural and processual measures alone would contribute to safer care. The article posits that healthcare organisations in India need to look beyond the structural-procedural efforts and evaluate an essential component of healthcare which serves to bind these efforts; that of safety culture. The paper draws on literature from health services and safety culture research as well as news articles in order to examine adverse incidents in care, safety theories and assess whether structural and procedural efforts would alone contribute to safer care. The review examines the current burden of adverse events in care as well as patient safety initiatives in the Indian context. An emergent strategy comprising policy, regulatory and structural measures has evolved over a period of time to address various facets of patient safety. Global research evidence over the years suggests that such structural-processual measures alone have not been able to address the burden of adverse events in care. Safety culture has emerged as an important concept binding quality and performance measures in most high-risk organizations including healthcare. Institutionalizing safety culture has become a strategic priority in most health care organisations globally. Taking a complex adaptive system perspective, the paper argues that synergizing policy, regulatory and structural-processual measures with safety culture engineering at multiple levels would fetch greater dividends in the Indian patient safety landscape.
\end{abstract}

Keywords: Complex Adaptive System, Developing countries, Patient safety initiatives, Patient safety culture

\section{Introduction}

The landscape of patient safety in Indian healthcare has been dotted by several incidents large and small, across urban and rural settings; from highly specialized tertiary care to the ubiquitous general practitioner. There are those incidents which have put the national glare on lack of safety foundations in seemingly safe health care environments. Recent in the healthcare horizon has been the horrific death of 93 patients owing to a fire in a super-specialty private health care establishment of a first-tier Indian city [1]. Preliminary reports found several glaring lapses in safety norms. Despite the presence of fire sensors, the smoke alarms did not function the fateful day since it was alleged that doctors and staff habitually deactivated the smoke alarms in order to smoke indoors. As the fire grew, inadequate fire-fighting knowledge of hospital staff worsened the scenario [2]. Multiple interconnected organizational and external factors, such as lack of design redundancies in the ventilation system [2], flouting of safety norms by the hospital authorities [3], lack of egress for the fire-fighting operations [4], served to focus the spotlight squarely on the questionable status of safety norms, culture and ineffective regulation prevalent in healthcare establishments [5,6]. This healthcare establishment was in the national limelight yet again in 2013 for a long-pending case of medical negligence wherein the compensation awarded to the victim's kin was the highest in the history of medical negligence cases in India [7]. While these are recent events, past instances of preventable medical errors in varied clinical settings have also been widely publicized, including the deaths of 18 pregnant women due to contaminated I.V fluids at a specialty government hospital [8], unsafe injection practices leading to Hepatitis-B epidemic and deaths in a north-eastern district of India [9] as well as individual cases indicating gross lapses in medical care [10-13]. A greater concern is that these incidents could very well be the proverbial tip of the iceberg. Increasing emphasis is being placed worldwide on patient safety and measures are being taken towards ameliorating the global burden of harm. Promoting a culture of safety has become one of the pillars of the patient safety movement. In the Indian context few papers have examined the role of patient safety culture and strategies for institutionalizing it. This paper aims to review adverse events in care and the safety initiatives that have taken so far in the Indian context. The paper also makes suggestions, based on a complex adaptive system perspective, for institutionalizing patient safety culture.

II. Safety Events in Healthcare: Hard-Earned Lessons or Lessons Hardly Learnt?

Highly publicized incidents of medical errors as well as safety lapses in several countries have led to pressure for change. In U.K several public enquiries into medical scandals led the editor of the British Medical 
Journal to declare that the era of medical self-regulation was over: 'All changed, changed utterly' [14]. The watershed report by the Institute of Medicine (IOM), "To Err is Human: Building a Safer Health System" [15] put patient safety concerns in the media spotlight internationally, galvanizing the momentum for action against the inaction on medical errors in the healthcare industry [16].

Following the IOM report, a number of empirical studies by different countries over the years [17-21] have revealed high rates of unsafe acts and their consequence. A recent study estimated that 43 million adverse events occur globally of which an alarming two-thirds occur in low-income and middle-income countries [22]. They estimated 5.2 million medical injuries occur in India annually, based on global averages for low and middle income countries [23].

In the Indian context, research on adverse events in care is limited [24] ; with studies carried out mostly in secondary and tertiary care settings. These studies have sought to highlight rates of adverse events including Hospital Acquired Infection (HAI) [25-28], medical errors [24,29] as well as medication errors [30-33]. While the overall HAI rate in acute care settings was found to vary between 33.5 per cent [25] to 4.4 per cent [27]; medical errors varied from 31.5 per cent [24] to 35 per cent [29], and the overall incidence of medication errors varied between 34 per cent [30] to 9.6 per cent [31]. Studies have also attempted to analyse adverse events on a pan-India basis. One such study has been the Indian Intensive Care Case Mix and Practice Patterns (INDICAPS) study; a large scale, multicenter survey launched to gather information about ICUs, patients in ICUs, the type and severity of illness, monitoring and therapeutic abilities as well as types of infections. The study found that 26 per cent of patients in ICUs contracted sepsis; one in four patients admitted in ICUs contracted sepsis in the hospital's emergency departments, with sepsis claiming one out of two patients [34]. A common thread found in most studies however is the lack of active surveillance \& paucity of data as limiting the evidence base.

\section{Addressing Safety Events in Healthcare: A Call to Arms}

The health care industry appeared to be far behind other high risk industries in ensuring basic safety. In 2002, the 55th World Health Assembly adopted a resolution which urged countries to place increased emphasis on the issue of patient safety and strengthen safety and monitoring systems in healthcare. In order to understand the scope of the issues facing policy-makers and researchers involved in improving the safety in health care, the World Health Organization (WHO) created an international alliance; the World Alliance for Patient Safety (WAPS), which was launched in May 2004 [35]. WAPS launched seven major programmes, including the successful hand hygiene and surgical checklist campaigns which have been adopted globally [36-38].

Ongoing research on patient safety has received a fillip in the form of funding by bodies such as World Health Organization [39], US federal governmental and private agencies such as Agency for Healthcare Research and Quality (AHRQ) and National Patient Safety Foundation (NPSF) respectively [40]. Health system reforms have seen the gradual establishment of standards setting bodies, either private such as Joint Commission in the U.S [41], as well as public bodies such as National Institute for Clinical Excellence (NICE) in United Kingdom [42]. Globally, structural changes have been a large part of health system reforms focusing on safety [43].

Fledgling steps have been taken by Indian health organizations to address the increasing evidence base of patient safety events. Recent efforts at standardization have involved the setting up of a national voluntary accreditation structure, the National Accreditation Board for Hospitals and Healthcare Providers (NABH) in 2006 by the Quality Council of India (QCI) [44]. NABH standards comprise ten chapters with 102 standards and 636 objective elements [45]. NABH currently accredits hospitals, medical laboratories, small healthcare organizations, primary and community healthcare centres, blood banks, dental facilities, as well as imaging facilities [46]. Sustained efforts by patient advocacy groups to address substandard infrastructure and quality in private medical establishments led to the Clinical Establishment Act, a central legislation being passed in 2010 to ensure registration and uniform enforcement of minimum standards across both public and private sectors; from all recognized systems of medicine [47,48]. Normative pressure to change has also come from the global launch of patient safety initiatives. The Indian confederation for Healthcare Accreditation (ICHA) began collaborating with WAPS, the objective being training, identification and setting up of database for adverse incidents in hospitals, nursing homes and clinics [49]. Recognizing the need to address adverse drug events, the government of India initiated the National Pharmacovigilance Programme in early 2005, which was restarted as the Pharmacovigilance programme for India (PvPI) operational from mid-2010 [50]. The All-India Institute of Medical Sciences (AIIMS) in collaboration with WHO has also launched the National Initiative on Patient Safety (NIPS) in 2009, underscoring the increasing priority to patient safety. NIPS aims to train and sensitize clinical professionals across the country on adverse events, reporting systems and patient safety practices[51]. The past few years have also seen international healthcare conferences organized in India by major healthcare providers and academic institutes. These conferences have focused on showcasing best practices in patient safety in India, the role of technology in safety as well disseminating successful patient safety innovations and interventions from other countries[52]. 
Summarizing, pressure for change in India has come from international bodies advocating safer establishments and patient care. The pressure has been sustained by patient advocacy groups, professional bodies and mounting evidence of harm from deficient quality in care. An emergent strategy comprising policy, structural and processual measures has evolved over a period of time. As a strategy, emergent or otherwise, would policy-structural-procedural measures suffice? Studies in developed and developing countries have shown that despite policies for safety, advancements in safety practice and technology, the burden of adverse events remains a challenge. Are we overlooking something? The following section explores the role of safety culture as the missing link binding the myriad efforts.

\section{Rethinking Patient Safety- Evolving Role of Safety Culture in Healthcare}

Advocates of strategic cultural change in healthcare make a number of implicit assumptions, the basic assumption being that organizations possess discernible cultures, which affect quality, safety and performance $[43,53,54]$. Appeals for culture change draw on a belief that culture is related to organizational performance [43]. The management of organizational culture has been viewed as a necessary part of health systems reform in the US [55] as well as UK [56]. Patient safety culture assessments are required by international accreditation organizations and allow the healthcare organizations to obtain a clear view of the strengths and weaknesses of their safety culture [57]. This is essential since healthcare systems traditionally function as professionalized bureaucracies [58]. Chronic underreporting, "code of silence' among professionals, professional hierarchies, organizational silences akin to the Abilene paradox have created siloed categories of unsafe cultures in themselves [59]. Contributing further is an insular focus on indices such as waiting time, bed occupancy rates, operation theatre utilization rates to name a few, which do not lend themselves to detecting subtler interactions in the system which could potentially lead to adverse events.

Safety culture, a subset of organizational culture, has been embraced by a diverse range of high-risk industries such as aviation, nuclear power, and chemical engineering, wherein safety is a top priority and safety checks have been integrated into all organizational activities [60]. The term 'safety culture' first became popular following the Chernobyl nuclear disaster when it was suggested by the International Atomic Energy Agency (IAEA) that operating nuclear power plants can reduce accidents and safety incidents by developing a "nuclear safety culture' [61]. Safety culture has since been formally adopted as a required element of nuclear power safety by the IAEA [62]. Safety culture has been defined as 'a global phenomenon and encompasses the norms, values and basic assumptions of an entire organization' [63].

Work on safety culture in high risk industries such as aviation and nuclear industries have informed health care [64]. Initially, healthcare focused on human error [55]; specifically those errors associated with perceptual limitations [65] and employee behavior [66]. This reflected the traditional person-centered philosophy in addressing errors with little focus on system-oriented perspectives [67]. Moving away from the focus on individual attitudes and behavior, two schools of thought based on social science and engineering have addressed the organizational aspects of safety; namely the Normal Accident Theory (NAT) [68] and High Reliability Organizations (HRO) theory [69-72]. While NAT posits that accidents are inevitable or normal in interactively complex and tightly coupled systems, the more optimistic HRO theory asserts that organizations can become highly reliable and avoid system accidents by creating appropriate behaviors and attitudes or 'collective mindfulness' [71].

Another approach has been the system-oriented perspective; with examination of organizational structures and system processes [73 74], system reliability [75], and management practices [76], which have all emerged as specific areas of safety culture research. James Reason's (1995) 'Swiss cheese' model comprising 'active failures' and 'latent conditions' posited that errors occurred from the convergence of multiple and complex contributing factors. The systems approach gained widespread acceptance and has been used to assess safety in healthcare [77]. Another model which expanded on Reason's model was Vincent et al. (1998) nested hierarchy of factors which included seven categories including patient characteristics. It has been used in assessing safety and safety attitudes in healthcare. [78-80]

Increasingly however, complexity thinking is being applied in the context of health care systems; with health care organizations being likened to complex adaptive systems (CAS). A complex adaptive system is a collection of individual agents who have the freedom to act in ways that are not always totally predictable, and whose actions are interconnected such that one agents actions changes the context for other agents[81]. The boundaries of a complex system are arbitrary; for instance, medical professionals as a group are embedded in an organizational group, which is embedded in a regional health care system, which is embedded in a socioeconomic-political system and so on. According to the CAS perspective, key to the strategy of designing safer cultures is acceptance of the fact that people populating systems are non-linear and have emergent behavior which could be one of innovation or error $[82,83]$. More often than not, detailed policies and protocols don't have the intended effect since local context, political dynamics and resistance or reluctance by people themselves may thwart the process. The basic tenets of CAS include setting a general direction, prohibitions as 
well as providing for resources or permission [84]. Efforts could thereby have a broad framework, regulation and boundary setting as well as focus on incentives and resources. The Institute of Medicine (2001) took cognizance of the CAS perspective and consequently their second report Crossing the Quality Chasm laid down general aims rather than a detailed blueprint for an ideal health care system in the United States [85].

\section{Designing Safer Cultures}

While evidence is being accrued and patient safety initiatives are being rolled out in India, a greater challenge will be establishing a cultural transformation of the healthcare system. Taking a cue from CAS perspective, several measures can be taken at multiple levels towards institutionalizing patient safety culture. The measures suggested are based on similar innovations in U.S and U.K healthcare systems which have seen constant evolution, adaptation and innovation in the field of patient safety. The measures suggested are based on policy and regulation, workforce and training, research and development, incentives as well as engagement of key stakeholders including policy makers, patients, healthcare providers and administrators (Fig. 1). Table 1 outlines a few such initiatives which could be taken at National, State and Local levels.

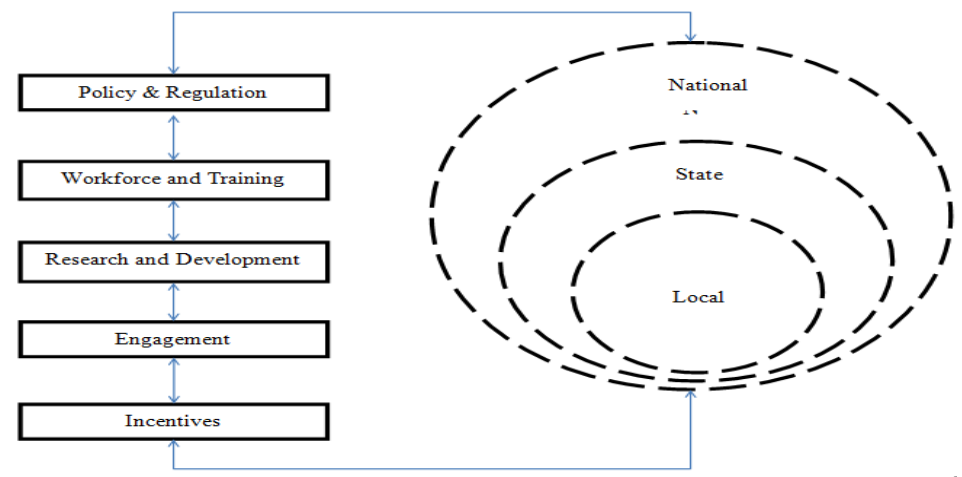

Figure 1: CAS perspective of measures aiding the institutionalization of patient safety culture

Table 1: Engineering the culture of patient safety

\begin{tabular}{|c|c|c|}
\hline & National and State level & Healthcare Organization level \\
\hline \multirow[t]{2}{*}{ Policy and Regulation } & $\begin{array}{l}\text { Creation of a single umbrella organization addressing patient } \\
\text { safety related concerns would help to centralize patient safety } \\
\text { taxonomy, standard setting, surveillance as well as training and } \\
\text { development. }\end{array}$ & $\begin{array}{l}\text { At the organizational level, a prerogative } \\
\text { should be instituting policies and } \\
\text { protocols for patient safety practices, } \\
\text { encouragement of error reporting, } \\
\text { transparency in communication as well } \\
\text { as accountability in care. }\end{array}$ \\
\hline & $\begin{array}{l}\text { Policies for disclosure of adverse events should be defined. } \\
\text { Establishing a system for reporting could include State- } \\
\text { wide voluntary reporting systems which could feed into a } \\
\text { national registry. Policy would need to be aided by } \\
\text { regulation for better results. }\end{array}$ & \\
\hline $\begin{array}{l}\text { Workforce and } \\
\text { Training }\end{array}$ & $\begin{array}{l}\text { A critical need is the dissemination of patient safety } \\
\text { practices. While headway has been made by National } \\
\text { Initiative on Patient Safety in instituting training for key } \\
\text { stakeholders from healthcare institutions across the country, } \\
\text { expanding this initiative at State levels with inclusion of } \\
\text { smaller healthcare organizations as well as general } \\
\text { practitioners would percolate efforts to grass root levels }\end{array}$ & $\begin{array}{l}\text { Directed and consistent training is an } \\
\text { important part of organizational efforts to } \\
\text { improve skills and sensitize staff on safety } \\
\text { issues. Considering the fact that hospitals } \\
\text { face high attrition rates especially amongst } \\
\text { nursing cadre[86], a robust training } \\
\text { programme is essential for consistency in } \\
\text { knowledge and performance across all cadres }\end{array}$ \\
\hline Incentive & $\begin{array}{l}\text { Voluntary efforts such as accreditation lay down policies } \\
\text { and protocols in patient safety. However the slow and } \\
\text { variable uptake of NABH accreditation has seen only } 195 \\
\text { hospitals accredited out of roughly } 40,000 \text { hospitals and } \\
\text { healthcare establishments; with few States taking the lead } \\
\text { [87]. While policy incentives such as CGHS empanelment } \\
\text { exist [88] and making accreditation compulsory for } \\
\text { empanelment by insurers has been mooted, an added } \\
\text { incentive would be increasing consumer awareness on the } \\
\text { merits of care provided in accredited hospitals }\end{array}$ & $\begin{array}{l}\text { Incentivizing safety behavior either in the } \\
\text { form of recognition as well as celebration of } \\
\text { safety efforts and innovations. }\end{array}$ \\
\hline Engagement & $\begin{array}{l}\text { Engagement of key stakeholders including healthcare } \\
\text { providers, administrators and importantly patients } \\
\text { including patient advocacy groups at the National and State } \\
\text { levels. }\end{array}$ & $\begin{array}{l}\text { The success of patient safety initiatives } \\
\text { would hinge on involvement of key } \\
\text { stakeholders including clinical, nursing, } \\
\text { support and managerial staff. Apart from } \\
\text { formal systems, informal systems too should } \\
\text { be tapped, for instance clinical professionals }\end{array}$ \\
\hline
\end{tabular}




\begin{tabular}{|c|c|c|}
\hline & & $\begin{array}{l}\text { would be more likely to own a process if } \\
\text { influenced by opinion makers from their } \\
\text { field. }\end{array}$ \\
\hline & & $\begin{array}{l}\text { An invested leadership - 'WalkRounds' by } \\
\text { senior leaders and executives to patient care } \\
\text { areas to gain a first-hand assessment of safety } \\
\text { concerns[89]. }\end{array}$ \\
\hline $\begin{array}{l}\text { Research and } \\
\text { Development }\end{array}$ & $\begin{array}{l}\text { A central body with research capacities and resources } \\
\text { should be designated to direct research patient safety } \\
\text { events, efficacy and outcomes of safety interventions in } \\
\text { care. }\end{array}$ & $\begin{array}{l}\text { Research in healthcare organizations could } \\
\text { focus on assessing safety interventions and } \\
\text { their outcomes. Further, reliable and } \\
\text { validated surveys could be conducted to } \\
\text { understand the safety culture in the } \\
\text { organisation }[90,91] \text {. }\end{array}$ \\
\hline
\end{tabular}

Safety efforts would need to begin with establishing a dedicated infrastructure and capacity-building to address the creation of a patient safety framework. Similar to the ambit of patient safety bodies such as AHRQ and NPSF in U.S, parameters such as quality indicators, evidence based guidelines; training and dissemination of best practices as well as patient safety culture surveys could be initiated centrally. Patient safety culture assessments, required by international accreditation organizations, have allowed healthcare organizations to obtain a clear view of the strengths and weaknesses of their safety culture[57]. Such surveys could be conducted confidentially and would help to establish benchmarks. Apart from identifying problem areas it would also allow participating establishments to assess themselves against national or State benchmarks.

A greater challenge would be instituting disclosure of adverse events. Disclosure is a complex notion and has been heavily debated by healthcare professionals. Of prime concern is shielding the patient safety data from legal proceedings as well as protection of whistle blowers [92]. In the Indian context, policy for disclosure would need to be aided by regulation. For instance Patient Safety Organizations (PSO), came into being in U.S with passage of The Patient Safety and Quality Improvement Act of 2005, which allowed for voluntary and confidential reporting of patient safety events by hospitals, doctors and other healthcare providers [93].

Research on adverse events and systemic issues in care in the Indian context has lagged behind. A greater thrust is needed for evidence based action. Policy incentives, infrastructure and funding would be drivers for research. Research capabilities would help in building the evidence base of adverse events as well as evaluation of safety interventions. Research outcomes would drive implementation of evidence based interventions as well as direct strategic allocation of resources.

At the national and State level, engaging with key stakeholders including healthcare professional bodies, patient advocacy groups, healthcare industry and administrator groups, would be necessary for the success of any initiative as well as addressing conflicting concerns.

Additional measures have been proposed at the organizational level based on successful safety innovations in the healthcare field in several countries and which could be easily adopted in the Indian context. For instance, simple concepts such as 'WalkRounds' by senior leaders and executives to patient care areas in order to discuss patient safety issues have paid dividends. Discussions at the front-lines of care indicate an invested senior leadership and a well-organized support structure [89,94].

To summarize, taking a cue from available evidence of best practices and innovations, policy incentives and regulatory aids, a framework for safety cultural transformation is being espoused. The framework could be expanded to include several more facets of patient safety. Factors such as lack of infrastructure and trained manpower, workload and attrition are ubiquitous realities in the Indian healthcare system. In the light of these realities, the paper has limited itself to those measures which could be adopted despite resource constraints.

\section{Conclusion}

'One's destination is never a place, but rather a new way of looking at things' [95]

Safety interventions in healthcare are manifold in the form of improved technology, processes and medical advances, enabling greater and safer therapeutic care. Safety science and the presence of underlying safety theories have not necessarily translated into an error-free healthcare sector. Murphy's Law thrives in high risk organizations such as healthcare.

Policy makers and healthcare administrators in the Indian context need to consider the concept of safety culture as the critical link binding myriad safety efforts in the organization. Dismissing the concept as an abstract trait far removed from 'machine-like' ethos of healthcare organizations would only limit the understanding of safety in complex systems such as healthcare.

Based on studies and experiences of several countries, what seems certain is that safety systems are impacted by culture which also set limits to structural and procedural changes. Taking a cue, an amalgamation of structural-procedural-cultural efforts at the national, State and local levels would foster greater gains in the safety outlook of Indian healthcare organizations. 


\section{References}

[1]. Deccan Herald. Week after AMRI hospital fire, anger still not doused, available at: http://www.deccanherald.com/content/212225/weekamri-fire-anger-still.html. 2011.

[2]. Biswas S. Smokers turned off detectors at AMRI hospital; available at: http://www.hindustantimes.com/India-news/Kolkata/Smokersturned-off-detectors-at-AMRI-hospital/Article1-781134.aspx. Hindustan Times, 2011.

[3]. AMRI hospital fire in Kolkata: AMRI flouted fire-safety norms at will. The Times of India: Kolkata, 2011.

[4]. AMRI hospital fire in Kolkata: Tiny lane delayed fire fighting operation, 2011.

[5]. Madhok R, Roy N, Panesar S. Patient Safety in India: Time to spped up our efforts to reduce avoidable harm. The National Medical Journal of India; Vol 25 (3) 2012:129-31

[6]. Nandraj S. Unregulated and Unaccountable: Private Health Providers. Economic \& Political Weekly; Vol 47(4) 2012:12-17

[7]. Medical negligence: SC orders damages of Rs $5.96 \mathrm{cr}$ in Anuradha Saha case. IBL Live -India, 2013.

[8]. Gupta N, Srinivasan S. Serial maternal deaths in a tertiary care hospital: some questions. Indian Journal of Medical Ethics; Vol 8 (2) 2011:70-72

[9]. S.J.Gandhi. Hepatitis B outbreak investigation report in Sabarkantha District, Gujarat State, February 2009. International Journal of Medicine and Medical Sciences; Vol 3 (5) 2011:109-21

[10]. Nayak M. Live Mint \& The Wall Street Journal. Medical negligence: SC awards Rs1 cr compensation, 2009.

[11]. Mishra L. Mirror Bytes: Probe confirms Sion Hospital gave patient wrong blood type, available at: $\mathrm{http}: / / \mathrm{m}$.mumbaimirror.com/index.aspx Page $=$ article \&sectname=News\%20\%20City\&sectid=2\&contentid=20111214201112140240397958f bfc02c. 2011.

[12]. Mishra L. MumbaiMirror.com. 79-yr-old suffers fractures in ICU fall, son goes to cops, available at: http://www.mumbaimirror.com/article/2/201207132012071302202497ada92e2/79yrold-suffers-fractures-in-ICU-fall-son-goes-to-cops.html. 2012.

[13]. 'Our baby died a painful death'. available at: http://www.deccanchronicle.com/130208/news-current-affairs/article/\%E2\%80\%98our-babydied-painful-death\%E2\%80\%99. Deccan Chronicle, 2013.

[14]. Smith R. All changed, changed utterly. British Medical Journal; Vol 316, 1998:1917-8

[15]. Kohn L, Corrigan J, Donaldson M. To err is human: building a safer health system. Washington DC: National Academy Press, 1999.

[16]. Blendon R, DesRoches C, Brodie M, et al. Views of practicing physicians and the public on medical errors. New England Journal of Medicine 2002:1933-40

[17]. Schiøler T, Lipczak H, Pedersen B, et al. Incidence of adverse events in hospitals. A retrospective study of medical records Ugeskrift for Laeger,Vol 163(39) 2001:5370-8

[18]. Baker R, Norton P, Flintoft V, et al. The Canadian Adverse Events Study: the incidence of adverse events among hospital patients in Canada. Journal de l'Association Médicale Canadienne (Canadian Medical Association Journal); Vol 170(11) 2004:1678-86

[19]. Barker K, Flynn E, Pepper G, et al. Medication Errors Observed in 36 Health Care Facilities. Archives Internal Medicine Vol 162(16) 2006:1897-903

[20]. Aranaz-Andres J, Aibar-Remon C, Vitaler-Murillo J, et al. Incidence of adverse events related to health care in Spain: results of the Spanish National Study of Adverse Events. Journal of Epidemiology \& Community Health; Vol 62 2008:1022-29

[21]. Morimoto T, Sakuma M, Matsui K, et al. Incidence of Adverse Drug Events and Medication Errors in Japan: the JADE Study. Journal of General Internal Medicine, Vol 26(2) 2011:148-53

[22]. Jha A, Larizgoitia I, Audera-Lopez C, et al. The global burden of unsafe medical care: analytic modelling of observational studies. British Medical Journal of Quality and Safety ; Vol 22 2012: 809-15

[23]. Sinha K. The Times of India. The Times of India: India, 2013.

[24]. Kumar S, Chaudhary S. Medical errors and consequent adverse events in critically ill surgical patients in a tertiary care teaching hospital in Delhi. Journal of Emergencies, Trauma, and Shock; Vol 2 (2) 2009: 80-84

[25]. Agarwal R, Gupta D, Ray P, et al. Epidemiology, risk factors and outcome of nosocomial infections in a Respiratory Intensive Care Unit in North India. The Journal of Infection; Vol 53 (2) 2006: 98-105

[26]. Anbumani N, Kalyani J, Mallika M. Prevalence of Methicillin-Resistant Staphylococcus aureus in a Tertiary Referral Hospital in Chennai, South India. Indian Journal of Practicing Doctors 2006: 8-9

[27]. Mehta A, Rosenthal VD, Mehta Y, et al. Device-associated nosocomial infection rates in intensive careunits of seven Indian cities. Findings of the International Nosocomia Infection Control Consortium (INICC). Journal of Hospital Infection; Vol 67 2007: 168-74

[28]. Thomas D, Parameswaran N, Harish B. Catheter related blood stream infections in the paediatric intensive care unit: A descriptive study. Indian Journal of Critical Care Medicine; Vol 17 (3) 2013: 135-39

[29]. Rodrigues G, Anand Rao BH, Thiyagu R. Development of trigger tool for identifying adverse events in surgery: Experience of a pilot study. Asian Journal of Pharmaceutical and Health Sciences; Vol 3 (3) 2013: 791-99

[30]. Pote S, Tiwari P, D'Cruz S. Medication prescribing errors in a public teaching hospital in India: A prospective study. Pharmacy Practice; Vol 5(1) 2007: 17-20

[31]. Jain S, Basu S, Parmar V. Medication errors in neonates admitted in intensive care unit and emergency department. Indian Journal of Medical Sciences; Vol 63 (4) 2009: 145-51

[32]. Agrawal P, Sachan A, Singla R, et al. Statistical Analysis of Medication Errors in Delhi, India. Indo Global Journal of Pharmaceutical Sciences; Vol 2(1) 2012: 88-97

[33]. Thakur H, Thawani V, Raina R, et al. Noncompliance pattern due to medication errors at a Teaching Hospital in Srikot, India. Indian Journal of Pharmacology; Vol 45 (3) 2013: 289-92

[34]. Roy SD ' 1 in 4 ICU patients gets sepsis, 1 in 2 dies. The Times of India, 2012

[35]. Pittet D, Donaldson SL. Clean Care is Safer Care: The First Global Challenge of the WHO World Alliance for Patient Safety. Infection Control and Hospital Epidemiology; Vol 26 (11) 2005: 891-94

[36]. WHO. The Global Patiet Safety Challenge 2005-2006 "Clean Care is Safer Care". Geneva: World Health Organization, 2005.

[37]. WHO, Guidelines for Safe Surgery. Geneva: WHO Press, 2008

[38]. Haynes A, Weiser T, Berry W, et al. A Surgical Safety Checklist to Reduce Morbidity and Mortality in a Global Population. The New England Journal of Medicine 2009: 491-9

[39]. WHO, Small Research Grants for Patient Safety. Geneva: World Health Organization 2008

[40]. Parsons D. National Patient Safety Foundation (NPSF) and the Technology of Patient Safety. Nursing Outlook; Vol 51 (3) 2003: s25-6

[41]. Schyve P. The evolution of external quality evaluation: observations from te Joint Commission on Accreditation of Healthcare Organizations. International Journal for Quality in Health Care; Vol 12 (3) 2000: 255-58

[42]. Drummond M, Sorenson C. Nasty or Nice? A perspective on the Use of Health Technology Assessment in the United Kingdom. Value in Health; Vol 12 (Supp12) 2009: S8-S13

[43]. Scott T, Mannion R, Davies H, et al. Healthcare Performance and Organisational Culture. Abingdon: Radcliffe Medical Press, 2003.

[44]. NABH accreditation lauded. Quality India: A QCI Publication; Vol 2 (5) 2008. http://www.qcin.org/nbqp/qualityindia/Vol-2No5/health_page_4_9.php.

[45]. Hittinahalli V, Golia S. NABH Accreditation and its status in the Country. Al Ameen Journal of Medical Science; Vol 6 (1) 2013:3-6

[46]. NABH Accredited Hospitals. National Accreditation Board for Hospitals \& Healthcare Providers, 2012. 
[47]. Enactment of Clinical Establishments (Registration and Regulation Act) 2010. Press Information Bureau:Government of India, 2010.

[48]. Srinivasan S. Regulation and the Medical Profession: Clinical Establishments Act, 2010. Economic and Political Weekly; Vol 48 2013: 1416

[49]. Rajadhyaksha M. "Doctors, patients come together for healthcare", Times of India, [online], available at: http://articles.timesofindia.indiatimes.com/2009-04-20/mumbai/28001707_1_patient-safety-errors-hospital-administrators. Times of India, 2009.

[50]. Gupta Y. Ensuring Patient Safety - Launching the New Pharmacovigilance Programme of India. Pharma Times; Vol 42 (8) 2010

[51]. National Initiative for Patient Safety. AIIMS: Department of Hospital Administration, nd.

[52]. Apollo Hospitals Group to host two international conferences. The Time of India: Hyderabad 2012.

[53]. Nieva V, Sorra J. Safety culture assessment: a tool for improving patient safety in healthcare organizations. Quality and Safety in Health Care; Vol 12 (Suppl II) 2003: ii17-ii23

[54]. Schutz A, Counte M, Meurer S. Development of a patient safety culture measurement tool for ambulatory health care settings: analysis of content validity. Health Care Management Science; Vol 10 (2) 2007: 139-49

[55]. Kohn, L., Corrigan, J. and Donaldson, M. To err is human: building a safer health system. Washington DC: National Academy Press, 2000.

[56]. An organization with a memory: Report of an expert group on learning from adverse events in the NHS. London: Department of Health, 2000 .

[57]. Smits M, Wagner C, Spreeuwenberg P, et al. Measuring patient safety culture: an assessment of the clustering of responses at unit level and hospital level. Quality and Safety in Health Care: Vol 18 2009: 292-96

[58]. Mintzberg H. The Structuring of Organizations: A Synthesis of the Research. Englewood-Cliffs, NJ: Prentice Hall, 1979.

[59]. Henriksen K, Dayton E. Organizational Silence and Hiden Threats to Patient Safety. Health Services Research; Vol 41 (4 Pt 2) 2006, 153954

[60]. Third Report: Organising for Safety, ACSNI Study group on human factors. London: Health and Safety Commission, 1993.

[61]. Summary report on the post-accident review meeting on the Chernobyl accident (Safety series N75-INSAG-1). Vienna: International Atomic Energy Agency, 1986.

[62]. Safety Culture ( Safety Series No.75-INSAG-4). Vienna: IAEA, 1991.

[63]. Measuring Safety Culture. London: The Health Foundation, 2011.

[64]. Helmreich R. On error management: lessons fromn aviation. British Medical Journal; Vol 320 (7237) 2000: 781-85

[65]. Rasmussen J. The concept of human error: Is it useful for the design of safe systems in health care? Risk and Safety in medicine. London: Elsevier, 1999: 31-47.

[66]. Vuuren W. Organisational failure: Lessons from industry applied in the medical domain. Safety Science: Vol 33 (1-2) 1999: 13-29

[67]. Palmieri PA, Delucia PR, Peterson LT, et al. The anatomy and physiology of error in adverse healthcare events. In Advances in health care management: Patient safety and health care management, Vol 7. Bingley, UK: Emerald Group Publishing Limited, 2008: 33-68.

[68]. Perrow C. Normal Accidents: Living with High-Risk Technologies. New Jersey: Princeton University Press, 1999.

[69]. La Porte TR. High Reliability Organizations: Unlikely, Demanding and at risk. Journal of Contingencies and Crisis Mangement; Vol 4 (2) 1996: 60-71

[70]. Roberts KH. Managing high reliability organization. California Mangement Review; Vol 32(4) 1990:101-14

[71]. Weick K, Roberts K. Collective mind in organisations: heedful interrelation on flight decks. Administratie Science Quarterly; Vol 38 (3) 1993: $357 \mathrm{ff}$

[72]. Weick K, Sutcliffe K, Obstfeld. Organising for High Reliability: Processes of Collective Mindfulness. Research in Organizational Behaviour. Stamford: JAI Press Inc. , 1999.

[73]. Leveson NG. New accident model for engineering safer systems. Safety Science; Vol 42 (4) 2004: 237-70

[74]. Wachter RM. The end of the beginning: patient safety five years after "To Err is Human". Health Affairs; Vol 23 (11) 2004: 534-45

[75]. Amalberti R, Auroy Y, Berwick D, et al. Five system barriers to achieving ultrasafe health care. Annals of Internal Medicine; Vol 142 2005: 756-64

[76]. Konteh FH, Mannion R, Davies HT. Clinical Governance views on culture and quality improvement. Clinical Governance; Vol 13 (3) 2008: 200-07

[77]. Stanhope N, Vincent C, Adams S, et al. Applying human factors methods to clinical risk management in obstetrics. British Journal of Obstetrics and Gynaecology; Vol 104 1997:1225-32

[78]. Neale G, Woloshynowych M, Vincent C. Exploring the causes of adverse events in NHS hospital practice. Journal of Royal Society of Medicine; Vol 94 (7) 2001:322-30

[79]. Battles J, Lilford R. Organizing patient safety research to identify risks and hazards. International Journal for Quality and Safety in Health Care; Vol 12 (Suppl 2) 2003:ii2-ii7

[80]. Sexton J, Helmreich R, Neilands T, et al. The Safety Attitudes Questionnaire: psychometric properties, benchmarking data and emerging research. BMC Health Services Research; Vol 6 (44) 2006

[81]. Plsek P. Complexity and the Adoption of Innovation in Health Care. Accelerating Quality Improvement in Health Care: Strategies to Speed the Diffusion of Evidence-Based Innovations; 2003; Washington. National Committee for Quality Health Care.

[82]. Plsek P, Greenhalgh T. The challenge of complexity in health care. British Medical Journal; Vol 25 (6) 2001:40-46

[83]. Crossing the Quality Chasm: A New Health System for the 21st Century. Institute of Medicine. Washington D.C: National Academy Press, 2001.

[84]. Plsek P. Redesigning Health Care with Insights from the Science of Complex Adaptive Systems. Crossing the Quality Chasm: A New Health System for the 21st Century. Washington DC: The National Academies Press, 2001:309-22.

[85]. Kelley M, Tucci J. Bridging The Quality Chasm: To Improve Health Care We Need To Understand The Motivations Of Those Who Work In It. British Medical Journal; Vol 323 (7304) 2001,61-62

[86]. Khadria B. International nurse recruitment in India. Health Services Research; Vol 42 (3p2) 2007,1429-36

[87]. Accreditation brings patient safety to the fore: NABH chief. The Hindu: Madurai edition, 2013.

[88]. Misc. 4006/2009/CGHS/Comp. Cell Office of the Director, C.G.H.S, 2009.

[89]. Frankel A, Graydon-Baker E, Neppl C, et al. Patient Safety Leadership Walk Rounds. Joint Commision Journal on Quality and Safety; Vol 29(1) 2003:16-26

[90]. Colla JB, Bracken AC, Kinney LM, et al. Measuring patient safety climate: a review of surveys. Quality and Safety in Health Care; Vol 14 2005:364-66

[91]. Singla AK, Kitch BT, Weissman JS, et al. Assessing Patient Safety Culture: A review and Synthesis of the Measurement Tools. Journal of Patient Safety; Vol 2 2006:105-15

[92]. Mattie A, Ben-Chitrit R. Patient Safety Legislation: A look at Health Policy Development. Policy Politics \& Nursing Practice; Vol 8 2007: 251-61

[93]. Jones D, Jaffe R. Patient Safety Organizations: Champions for Quality. Journal Of Health Care Compliance; Vol 11(4) 2009:43-48

[94]. Thomas EJ, Sexton JB, Neilands TB, et al. The effect of executive walk rounds on nurse safety climate attitudes: a randomized trial of clinical units. BMC health services research; Vol 5(1) 2005:28

[95]. Miller H. Big Sur and the Oranges of Hieronymus Bosch. New York: New Directions Publishing Corporation, 1957. 